\title{
Involving local communities in flood risk management - urban and rural case studies
}

\author{
T. Coates \\ Flood Hazard Research Centre, Middlesex University, UK
}

\begin{abstract}
Changes in policy in the UK put an increasing emphasis on the involvement of local communities in the flood risk management process. Yet little is known about local communities and how they operate in our modern, mobile society. In fact many claim that local communities are being destroyed by increasing mobility and globalisation. Is there a local community we can engage in the flood risk management process? If so how should we go about doing this?

This research starts to address these questions by exploring both the social, collective responses to flooding and in turn the effect that flooding has on local social relations. This has been done through interviews with both residents and flood professionals in urban and rural locations in Yorkshire. Whilst there were differences between the rural and urban areas, similar underlying processes were identified.

There was not a single, straightforward 'local community' to be engaged. Rather there was a complex mix of overlapping networks and interests, where conflict as well as cooperation is possible. A number of key underlying factors were identified. To involve 'local communities' will require an evaluation of these in each location, whether urban or rural.

Keywords: flooding, local community, social networks, collective action, urban, rural, flood risk management, cooperation, conflict, qualitative.
\end{abstract}

\section{Why investigate 'local community'?}

The changing policy environment, both in the UK and elsewhere, places an increasing emphasis on the involvement of local communities in the flood risk management process. Whilst at face value involving the local community may seem a straightforward and laudable aim, closer inspection reveals a number of complexities. The intertwined concepts of community and local community have 
been hotly debated since their academic beginnings within the social sciences more than 200 years ago. (For discussions on the changing conceptualisation of community see: Crow [1], Day [2], Delanty [3]). Yet there has been relatively little recent empirical research on local communities and their processes in modern, mobile societies such as the UK. Rather there has been generalised theorising on the changing role of communities, often accompanied by a lament of the loss of community. In fact this pervasive 'community lost' discourse can be traced back to the concepts academic beginnings, which started with a concern that communities were being destroyed by industrialisation and urbanisation (Frazer [4]). The assumption that certain types of somewhat idealised rural settlements represented community meant that it was inevitable that communities should be seen as 'lost' once industrialisation took place. It is therefore essential to consider notions of urban and rural alongside those of community.

These apparently rather distant and theoretical discussions matter because they continue to profoundly influence our expectations of local communities today. The claim that local communities are being destroyed continues as loudly as before, and it has been given a new impetus with fears about post modernism and globalisation (Savage et al. [5]). The initial association made between rurality and community still shapes our expectations of local community. There is often a strong moral tone to these debates, with certain types or aspects of community being seen as superior and desirable. Yet whilst there has been considerable discussion of these issues, there has in recent years been little research with residents, looking at what they understand by local community and the processes that operate to construct these communities. This research does so with both 'urban' and 'rural' communities, to explore how local communities deal with flooding and in turn how they are affected by that flood experience.

The dominant discourse of community lost has led to a number of expectations about communities and their relation to urban and rural. In order to understand communities as they are, rather than as we would like them to be, we need to examine these underlying assumptions. So that we can both challenge our own taken for granted understandings and appreciate how these discourses influence residents' experiences of their local community. There is a tendency to expect local communities to be small, rural, harmonious groups of people, who live within a distinct, bounded and relatively isolated area. Where networks within the community are dense and interlinked, those outside the community are few and relatively unimportant. The community and the location are seen as synonymous, that is they are a community simply because they live together in that location. Community is understood only in positive terms, it is seen to be a good thing that we need more of, which perhaps explains its popularity in such a wide range of settings.

\section{The research approach}

This research sets aside normative definitions setting out what community should be, and through qualitative interviews with residents, explores local 
collective responses to flooding and in turn how local social relations are altered by the flood experience. Those with a responsibility for flood risk management in the chosen locations were also interviewed to allow professional understandings of community and how these shape their relationship with local communities to be investigated. There has been in recent years, through the vulnerability approach, recognition of the importance of research into the social as well as physical aspects of flooding. These studies have highlighted the impacts that floods have on people's lives beyond the more immediate physical effects and begun to reveal wider social disruption. However to date this has focused on impacts at the individual or household level (Twigger-Ross [6]). So relatively little is known about the impact on social interaction.

Given the ways in which the concept of local community is intertwined with those of urban and rural, both types of research location were selected. These have been given fictional names to protect the identity of those taking part. The urban Upbeck estate consists of 8 streets on the outskirts of the city of Leeds, where approximately 70 houses have been flooded. The estate has now flooded 3 times; in 2004, 2005 and 2007. The residents here have formed a flood action group. The rural location consisted of two villages in north Yorkshire. Alesby, a small isolated village located on the moors, which has approximately 60 residents and Haylton, larger in size with approximately 120 residents, and less isolated. These were both affected by flash floods in summer 2005, which were powerful enough to destroy roads and bridges. This paper explores the similarities and differences between the urban and rural fieldwork locations and identifies those underlying processes that are common to both.

The relationship between the mental, social and physical aspects of local community was found to be vital to understanding local community. Research on community has tended to concentrate on a particular aspect, rather then explore the interrelationship between the three. So whilst there is a vast community literature there has been little at the intersections. The mental aspects cover issues such as how the local community is understood and conceptualised and the ways in which residents identify or not with their local community. Social considerations include local social networks and how these are formed and maintained. Spatial aspects include physical details such as street layout, as well as more conceptual concerns on the nature of space. Together these aspects shape residents ability to respond collectively to flooding.

\section{Urban and rural case study results}

\subsection{Urban fieldwork location - Leeds}

Interviews with residents in Leeds revealed that the estate was the area that they identified with as local community. Whilst to the outsider the boundaries of the community were unclear there was considerable consensus amongst residents. An important factor in this identification was the lack of exits on and off the estate. Interviewees recognised that this helped create a boundary and good conditions for developing networks; “ "... we're kind of a small community, we're 
kind of one road in and one road out, with a few streets and, you know, as a community we would fare very well really. It's nicely compact". The population was relatively immobile, with most interviewees having lived in that part of Leeds all of their lives. Many had extended family living within a few miles and some lived on the same estate. Given the clear boundaries, strong identity and relative immobility a dense social network across the estate might be expected. However this was not the case, rather there were small clusters of networks focused on the residence and immediate neighbours. This was due to a lack of places for interviewees to meet other residents from their estate. Membership of local groups was also very low. These factors led to a reliance on chance meetings on the street to develop networks. This proved to be a slow process and produced the clusters described.

However the flooding led to an increase in local social networks. This was seen as an unexpected benefit of the flood and it was positively commented on by almost all interviewees. There were many remarks similar to the one following, from a man who has lived on the estate for 27 years. "Now we all talk to one another more. You find that people that you'd seen in passing, but you didn't really know anybody, now you do. So it makes quite a big difference in that respect". Whilst networks were agreed to have improved the focus was still largely on the street of residence. The shape of the street and position of the house was found to play a significant role in this. For example those living in a cul-de-sac found they formed a particular bond with the other residents in the end of the street where it opened to form a circular shape. The formation of a flood action group helped facilitate social networks across the estate, but this had largely benefited committee members.

The formation of the group also demonstrated the potential for conflict as well as cooperation within communities. Initially an informal group was set up to tackle some of the issues arising from the flood, in particular the cleaning out of the local beck. However disagreement arose over leadership and the handling of funds and for a time there was considerable animosity. This conflict was eventually resolved by the group splitting into two, with one becoming the Upbeck Community Association and the other a more formal flood action group. This flood group was formed with the assistance of the National Flood Forum (NFF) and took on a committee structure, with residents voting for positions such as chair, vice chair, secretary etc. Following the help of the NFF and the creation of a more formal structure the group appeared to work well. Committee members felt the group was worthwhile and that it gave them a visibility and influence they didn't have as individuals. Staff within the Environment Agency and the City Council also found working with the group to be a useful way of contacting and involving the community.

However there are a number of issues concerning the group and its relationship to the local community. Firstly the conflict raised the issue of who could be considered a legitimate leader and whether they were able to represent the group. Secondly there were complaints from some outside of the committee that they were not kept adequately informed of the group's actions (a complaint echoed by the group concerning the agencies involved). Information passed to 
them from official sources did not necessarily reach all the other residents or the information given was sometimes felt to be inadequate. This was partly due to differing expectations over the quality and quantity of communication, as were the problems between the flood group and the Environment Agency (EA) and the local council. Members were initially voted for but subsequent community wide meetings were not always well attended; do they still have their support? Given the difficulties of communication can the group be said to represent the community, is this a democratic process, and does it matter if it isn't?

By 2008 follow up interviews revealed that most of the original committee members had left the estate (although they had remained within a mile or so) leaving only the chairman. The EA, who took over responsibility for the local beck in 2006, had become much more involved and built up a good working relationship with key people within the community, in particular the remaining chairperson. They now had flood warnings and flood wardens in place and the city council were closely involved in developing systems to deal with a flood incident. The flood action group still existed in name but only had the one committee member. Although to some extent the flood wardens had taken on the committee role. Communication however still remained something of an issue. The chair believed that people should make the effort come to him if they wanted information, whereas residents expected information to be passed on to them. Important correspondence from official sources was usually sent individually to all households though, which ensured some information reached everybody.

Those who had taken on roles such as flood warden and were involved with the agencies had gained considerable expertise regarding the flooding. This had to some extent changed their status within the community. At public meetings they would answer questions on behalf of the staff present and residents would go to them with problems and complaints. They now held a status somewhere between that of other residents and the flood managers. Initially the flood action group was suspicious of 'officials' and saw them as an adversary. By 2008 there were good personal relationships in place, where known individuals were trusted and residents felt they were working together to solve the problem. Mistrust still existed and there was still a battle to be won but this was now with those higher up in the organisations or with the politicians who were understood to be in control of the finances, or with the system itself.

\subsection{Rural fieldwork locations - North Yorkshire}

The villages of both Alesby and Haylton had extensive networks prior to the flood with everybody feeling they knew everybody else in the village to some degree. Alesby had a small shop and tearoom as well as pub/hotel. The majority of networks were formed through people meeting at these locations or when walking around the village. Being very small and isolated it was quickly apparent who were residents and who were visitors. There were also a small number of annual, village wide events that attracted many residents, which helped cement the village identity. The village hall also hosted a limited number of groups so that some people came together for these. The church, although not extensively used, held some events that were more widely attended. The 
isolation of the village and the presence of various community structures (such as the village hall, shop and pub) combined to create a strong identification with the village and a sense that most people knew each other. It is interesting to note that the boundaries, which might have been expected to be very clear in such an isolated location, were actually quite blurred. Outlying farms might be included in the village or in a different village and some interviewees included a neighbouring hamlet as part of the village whilst others didn't. This did not prevent though those in the village clearly identifying with the village as their local community.

Haylton was in many ways an 'ideal' village. It had a very active village recreation group and an active Parish Meeting (similar to a Parish Council). There were many groups and activities that took place in the village hall and in the more recently acquired village sports ground. Residents generally knew each other well and they valued their reputation as a close knit village with an active social life. The wide range of groups, as well as many annual events such as the sports day meant that most people knew each other well. However unlike Alesby there was no village shop, pub or similar where residents could meet by chance. So if you were not members of same group it could be quite some time before you could expect to meet. If there had not been such an active social life, which took considerable effort from a number of people, networks would probably have been slow to develop. There is an effective communication system for the village, using email and village notice boards as well as leaflet or letter drops. There is also a village newsletter that is distributed to everybody. This multiple and proactive method of communication proved more effective than the more passive methods adopted in the other locations.

Mobility through the villages wasn't high but neither was it the situation that everybody had been there all their lives. In fact unlike Leeds, those who had moved in tended to have come from many miles away and had no connections with the area or any extended family nearby. In Alesby many of those moving in were professionals who were prepared to travel a considerable distance to work in order to be able to live in an attractive and active village. In Leeds absence from the community through work meant that some residents, reliant on bumping into neighbours to form networks, had few opportunities to develop local social relations. This was less of an issue in the villages, particularly Haylton, where there were clear community structures. This also allowed people moving into the village to be quickly incorporated into village life. There was also a strategy in place for welcoming newcomers to the village and inviting them to join in village events. This meant that any negative effects of mobility could be quickly overcome. Whereas in Leeds prior to the flood the lack of community structures, meant that even low residential mobility could have a detrimental affect on local networks.

The Parish Council responsible for Alesby covered a wide area that contained a number of villages. Its role within Alesby appeared to be quite limited and many residents had little idea of their responsibilities and activities. There was not a straightforward or close relationship between the village and the Parish. The situation in Haylton was quite different. They had a Parish Meeting and this 
was responsible only for the village. The Parish Meeting elects a Chair and a Clerk, but all electors are able to attend, speak and vote on proposals. Haylton Parish Meeting was active and most villagers attended at sometime and there had recently been well-attended meetings over a controversial proposal. The chair was active in the village and had been very involved after the flood. He acted particularly as a representative for the village when dealing with organisations such as various district and county council departments and utility companies.

In Leeds the flooding led to an increase in local networks where these had been relatively few. The formation of a flood action group and repeat flooding helped to sustain those links. In the rural locations where the existing links were already extensive it changed their quality rather then their quantity. Residents were often touched and surprised by the support they received. Relations that had been good became even closer, particularly between those who were seriously affected by the flooding. It also helped reinforce the villages' identity and villagers were proud of the way everyone had 'pulled together'.

\section{Common factors to be evaluated}

\subsection{Introduction}

The research reveals very different 'local communities' in the urban and rural locations both before and after the flooding. The flood situations are also very different with Leeds now having been affected three times. The individual cases are interesting and instructive but the main aim is to reveal the underlying processes and how together these construct a particular local community. Discussed below are a series of factors that need to be considered and assessed in each location to understand that particular community. These are closely interlinked and the form that one takes will affect the others. Understanding how they relate to one another is important.

\subsection{Boundaries}

The boundaries of a local community cannot simply be assumed. They may not follow those that are officially recognised or be obvious to the outsider. There may not even be a consensus within the community where the boundaries lie. Small rural locations tend to be easier in some respects because there is generally more convergence between residents, outsiders and official structures on what constitutes the local community. Boundaries can be mental as well as physical, for example they may focus on certain types of people rather than particular areas.

\subsection{Community structures}

Structures that operate within the local community can be very varied. They may focus on a particular building, but it is the events taking place that are important, a village hall may be largely unused for example. If there are local groups how often do they meet, are they largely for those within the community, is there 
much overlap of group membership? If there is a flood group how does it relate to the rest of the 'community'? Is there a clear community structure for residents to join and take part in? Is there a more informal structure based around meeting points such as shops? Is there a way of welcoming newcomers to the community?

\subsection{Social networks}

The extent and interlinking of social networks need to be considered. Residents do not need to know one another very well to work together in a flood situation but some kind of contact is necessary. Networks may be small, clustered and fairly isolated, particularly where there are few community structures or meeting places. If this is the case how might these be developed to form the basis of effective community involvement? If networks are more extensive, where do they overlap, is anybody excluded or marginal? What is the most effective way to access these networks?

\subsection{Spatial factors}

How do spatial factors from street level upwards impact on social relations? Certain places or parts of the street might form effective meeting points. Isolation of a population, through distance or a lack of entry points may reinforce its identity. Can these be used and developed? Physical features, such as major roads, or a steep slope may lead to a sense of separation between certain areas. Can intervention overcome factors limiting network development?

\subsection{Key people}

In all the locations there were key people involved in the construction of community however their role could be very varied. They range from the obvious such as Parish officials, through semi formal such as group organisers, through to the symbolic, where certain people in some way embody the communities 'spirit'. Official community leaders may not always be the most suitable. Also the types of people who are willing to take the lead in local groups are not always those that achieve universal popularity. Who will organisations work with? Who is chosen to work with the community also requires consideration. Relationships take time to develop, do they have this? Do they have the necessary skills to work with and gain the trust of this particular community?

\subsection{Communication}

Communication at all levels proved challenging: within the community, within particular groups, between groups and the rest of the community, between the community and official organisations, within organisations and between organisations. Dissatisfaction usually arose because of a mismatch between what those receiving the communications expected and what those giving it provided. 
Generally regular, proactive (taken directly to them), individualised communication in multiple formats is preferred by the receivers. Whereas those providing information find it easier to provide passive (for example simply advertising its availability), generalised information in few formats and then only when they feel there is significant information to convey. Discussion to reach and clearly identified, acceptable and realistic range of communication methods could overcome many of the difficulties.

\subsection{Potential divisions}

Harmony and cooperation cannot be taken for granted. Conflict within communities and groups is not unusual. As well as the conflicts discussed earlier there are a number of examples where the handling of post flood resources has caused conflicts (Fordham [7], Tapsell and Tunstall [8]). There is a need to identify any existing or potential conflicts within a community? Are there existing sensitivities that need careful handling? If there are problems how will these groups be dealt with or can the conflict be resolved? Any resources to be distributed must be considered carefully. What is considered fair by one person or group may be seen differently by others. So simply adopting what appears a fair system may not be sufficient.

\subsection{Post flood opportunities}

Whilst being flooded is a devastating experience which affects peoples lives for months and sometimes years it can provide some opportunities for the development of the local community. Immediately following the flood there is often a feeling of togetherness (sometimes known as the therapeutic community), can this be utilised? The movement to temporary accommodation can dissipate this so there may only be a limited opportunity. The shared experience of being flooded is an important component in developing post flood relationships; can this be harnessed with out causing a division with those not flooded? A flood action group can provide a focus for residents desire to take action and provide a useful way of working with the local community.

\section{The challenges and rewards of involving communities}

Local communities are varied and complex and the concept of community continues to be debated. Yet despite this complexity and ambiguity or maybe because of it, the term is very widely used. If involving local communities is to be more than rhetoric or a way of passing on responsibility then engaging with this complexity will be necessary.

The research found that local community continues to be relevant to people lives and as long as it is not too narrowly, or idealistically defined then examples of local community can still be found. How this operates and develops varies considerably but most people expressed a desire to help one another and an appreciation of local peoples support after a flood. However conflict as well as cooperation was revealed. A single, united, place bound community cannot be 
assumed. Rather the reality must be explored to understand the complex, dynamic relationships, existing between the mental, social and spatial aspects of community.

Involving a local community in flood risk management is not a quick fix. Getting to know and assessing the community is time consuming, building up trust and good relations probably even more so. Yet local people are already doing much for themselves, and often appreciate an opportunity to come together. By working together with those organisations involved in the flood risk management process there is the potential to develop more effective strategies for coping with flooding, as both have much they can learn from the other. The Leeds example shows how a sustained effort can overcome mistrust and move towards an effective relationship that utilises the local community structures.

\section{References}

[1] Crow, G. Community Studies: Fifty Years of Theorization. Sociological Research Online, vol.7, no. 3, www.socresonline.org.uk/7/3/crow.html, 2002.

[2] Day, G., Community and everyday life, Routledge: London and New York, 2006.

[3] Delanty, G., Community, Routledge: London and New York, 2003

[4] Frazer, E., The Problems of Communitarian Politics - Unity and Conflict, Oxford University Press, 1999.

[5] Savage, M., Bagnall, G., Longhurst, B., Globalization and Belonging, SAGE Publications Ltd. 2005.

[6] Twigger-Ross, C., The impact of flooding on urban and rural communities, $R \& D$ Technical Report SC040033/SR1, Joint Defra/Environment Agency Flood and Coastal Erosion Risk Management R\&D Programme Environment Agency, 2005.

[7] Fordham, M., Making Women Visible in Disasters: Problematising the Private Domain, Disasters, Vol. 22, No.2 June (Blackwell) pp. 126-143, 1998.

[8] Tapsell, S.M. and Tunstall, S.M., The Health and Social Effects of the June 2000 Flooding in the North East Region. Report to the Environment Agency. Enfield: Flood Hazard Research Centre, 2001. 